\title{
Future ethical implications and potential health consequences of nanotechnology research in Jordan: A scientometric analysis
}

\author{
Yazan Akkam ${ }^{1 *}$, Moawiah Khatatbeh ${ }^{2}$ \\ ${ }^{1}$ Department of Medicinal Chemistry and Pharmacognosy, Faculty of Pharmacy, ${ }^{2}$ Department of Basic Medical Sciences, \\ Faculty of Medicine, Yarmouk University, Irbid, Jordan \\ *For correspondence: Email: yazan.a@yu.edu.jo
}

Sent for review: 8 October 2020

Revised accepted: 19 January 2021

\begin{abstract}
Purpose: To evaluate the implanted legislation and regulations in Jordan, in order to minimize nanotechnology research-related health concerns.

Methods: In the first part, all nanotechnology published research in Scopus database and the Jordanian National Database for Researchers were mined. The growth in nanotechnology research was analyzed by calculating the relative growth rate (RGR), doubling time (DT), and compound annual growth rate (CAGR). Thereafter, the results were compared to global preferences. Furthermore, this research explored all possible factors that may influence decision-makers and health policies in Jordan. Results: Data analysis showed that the quantity of nanotechnology research in Jordan is exponentially increasing with RGR (1.96), DT (0.37), and CAGR (33\%) very close to the figures obtained worldwide. The trend line analysis $\left(R^{2}=0.9638\right)$ expected that more than $65 \%$ of nanotechnology research will be produced within the next 5 years. Moreover, no legislation has been adapted in Jordan to regulate nanotechnology research and industry.

Conclusions: Adopting nanotechnology without having any corresponding legislation constitutes a violation of the ethical codes of research, and ignorance of public safety. Moreover, the research suggests a set of steps to organize the crafting of nanotechnology and research in Jordan, and other similar contexts in developing countries.
\end{abstract}

Keywords: Nanotechnology, Public health, Toxicity, Relative growth rate (RGR), Doubling time (DT), Compound annual growth rate (CAGR)

\begin{abstract}
This is an Open Access article that uses a fund-ing model which does not charge readers or their institutions for access and distributed under the terms of the Creative Commons Attribution License (http://creativecommons.org/licenses/by/4.0) and the Budapest Open Access Initiative (http://www.budapestopenaccessinitiative.org/read), which permit unrestricted use, distribution, and reproduction in any medium, provided the original work is properly credited.

Tropical Journal of Pharmaceutical Research is indexed by Science Citation Index (SciSearch), Scopus, International Pharmaceutical Abstract, Chemical Abstracts, Embase, Index Copernicus, EBSCO, African Index Medicus, JournalSeek, Journal Citation Reports/Science Edition, Directory of Open Access Journals (DOAJ), African Journal Online, Bioline International, Open-J-Gate and Pharmacy Abstracts
\end{abstract}

\section{INTRODUCTION}

Nanotechnology is an emerging and rapidly growing field that is defined as" the study of the design, characterization, production, and application of structures, devices, and systems at the nanometer scale" [1]. Therefore, the global nanotechnology market is expected to exceed USD 124 billion in 2024 [2]. Nevertheless, the spiking number of nanotechnology applications is not coupled with an awareness of the potential health risks and toxicity of such nanomaterials. While investigating the potential effect of nanomaterials in the last two years, it has been 
found that the number of publications about the development of new nanomaterials is a lot more than the number of publications about the biological effect of nanomaterials or nanotoxicity $[3,4]$.

In general, materials at the nanoscale could impose higher risks than corresponding materials with larger particle sizes due to the increased particle surface area, in addition to other unique properties of materials at the nanoscale [5]. These nanomaterials could be more readily absorbed through the body and hence could accumulate in higher concentrations [1]. The toxicity of the nanomaterials has been elucidated, and a mechanism of action was proposed [6-9]. Nanomaterials, especially carbon-based nanomaterials, have been linked to chronic diseases [10], and in some cases are viewed as a potential cause of inflammation in different parts of humans' bodies [11,12]. Therefore, appropriate risk assessment and management are employed upon the handling of some nanomaterials worldwide. For instance, the US-department of Health and Human Services applies certain precautions on all nanomaterial products [13]. However, risk assessment policies and plans are lacking in developing countries due to a shortage of economic resources and financial strains.

Jordan, as a developing country, faces several socio-economic challenges, including the high unemployment rates, rapidly expanding labor force, and existing poverty levels. Moreover, Jordan has had to contend with a difficult external economic environment that caused a high influx of refugees to the country [14]. Subsequently, Jordan is in a huge financial problem with growing debt. The financial issue limits the possibilities of development in research and defines the Kingdom's priorities. Nanotoxicity is not Jordan's top priority. Therefore, Jordan is working with nanotechnology without any risk assessment plans or policies that may threaten the health of the public. To handle such a dilemma, this research evaluated the status of nanotechnology in Jordan, and emphasized the need for having certain legislation, professional regulations, and recommendations to reduce the potential health hazards of this trade on people, including researchers, producers, and consumers of nanomaterials.

\section{METHODS}

\section{Data collection}

"Scopus" database was accessed for all possible nanotechnology publications. The phrase "nano" with the asterisk truncation symbol was used, and the search in the database was specified to the title, keywords, and abstract from 1995 until December- 2019. Moreover, "Jordan" was used as the affiliation country. This technique "nano"based search detected different "nano"-phrases, such as nanotechnology, nanoparticles, nanomaterials, nanotoxicity, etc. In order not to miss any Jordanian publication relevant to nanotechnology (i.e. publications that are not listed on the Scopus database), the Jordanian National Database for Researchers, which is hosted by the Higher Council for Science and Technology, was mined for the word "nano". Data obtained were then sorted according to region, sectors (industrial or academic), and subject area.

\section{Data analysis}

To best understand the current and future nanotechnology research in Jordan, it should be compared with its worldwide equivalent. Therefore, 3 statistical measurements were calculated: Relative growth rate (RGR), doubling time (DT), and Compound annual growth rate (CAGR) which are used to compute the pace of published work in nanotechnology [6].

\section{Relative growth rate (RGR)}

Relative Growth Rate measures the increase in the number of articles per unit of time. Subsequently, this may be translated into the overall growth of research.

RGR was calculated as previously described using Eq 1 [15].

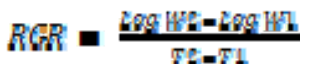

where RGR is the growth rate over the specific period of the interval. Log W1 is Log initial number of articles, W2 is Log final number of articles, T2 is the unit of final time, and T1 is the unit of initial time.

\section{Doubling time (DT)}

Doubling time refers to the period required for the number of articles to get doubled [16]. DT was calculated as in Eq 2 [15].

$27=\frac{9698}{\operatorname{RGR}}$

\section{Compound annual growth rate (CAGR)}

Compound annual growth rate (CAGR), which is a geometric progression that measures the 
growth over multiple periods [16], was calculated according to Eq 3 [15].

$C A G R=\{(\mathrm{Ve} / \mathrm{Vb})(1 / \mathrm{N})\}$

where $\mathrm{Ve}, \mathrm{Vb}$ and $\mathrm{N}$ are ending value, beginning value and number of years, respectively.

\section{Trend line analysis}

The coefficient of determination $\left(R^{2}\right)$ and equation for the both linear and exponential function of the Data (number of publications /year) was calculated using GraphPad Prism statistical software.

\section{RESULTS}

\section{Number of nanotechnology publications}

Jordan has a total of 26 universities and 54 community colleges [17]. Many of these institutions practice the craft of nanotechnology in one way or another. However, to realize the type and level of the involvement of such institutions in nanotechnology research, an extensive search on the "Scopus" database was executed. The search process resulted in a list of 1320 publications, including articles, reviews, proceedings, and theses. Considerable growth in the number of nanotechnology publications was found over time (Figure 1).

The trend of Jordanian scientific publications in nanotechnology is immensely increasing with time. For instance, publications in 1995 represent only $0.1 \%$ ( 2 articles) of the total number of nanotechnology publications between 1995 2019 , but it increased sharply reaching $20.5 \%$ (454 articles) in 2019, with a clear leap up in the number of publications observed in the period 2014 - 2019 (Figure 2).

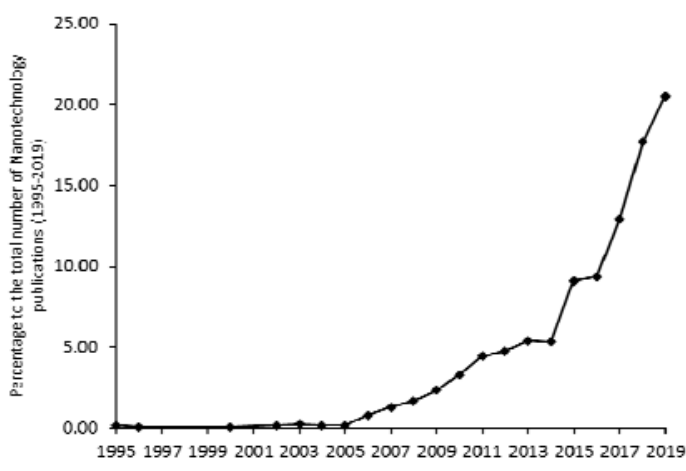

Figure 1: The publications trend as well as the percentage of nanotechnology articles in Jordan from 1995 to 2019

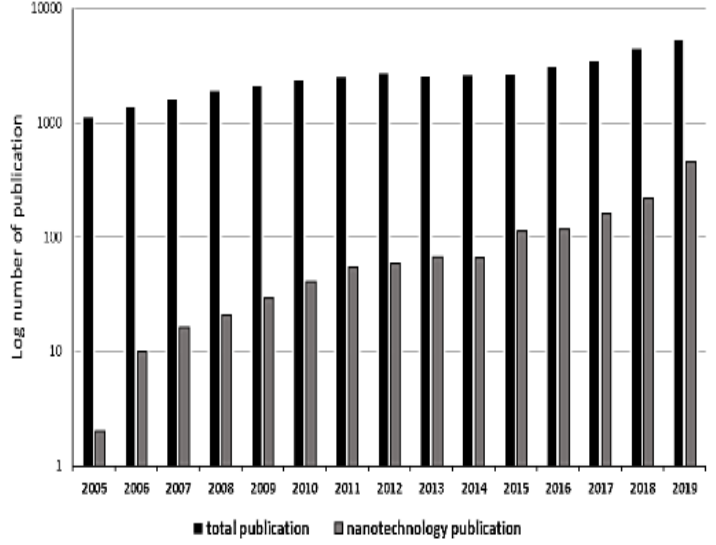

Figure 2: Comparison between the total number of scientific publications in Jordan and publications in nanotechnology (2005 - 2019)

Results showed that most nanotechnology industry and research are conducted within city limits, like Amman (36.8\%) and Irbid (24\%) (the two main cities in Jordan). These findings may be due to the fact that the largest and most recognized universities in Jordan are located in these regions. Namely: The University of Jordan in Amman and Jordan University of Science and Technology in Irbid.

\section{Relative growth rate (RGR)}

The RGR fluctuated throughout 1998 - 2007 before it dramatically increased (Figure 3 ). The growth of nanotechnology research at the onset (1998 - 2007) was slow and inconsistent, but it achieved solid linear growth from 2008 - 2019. The calculated RGR was 1.96 in 2019.

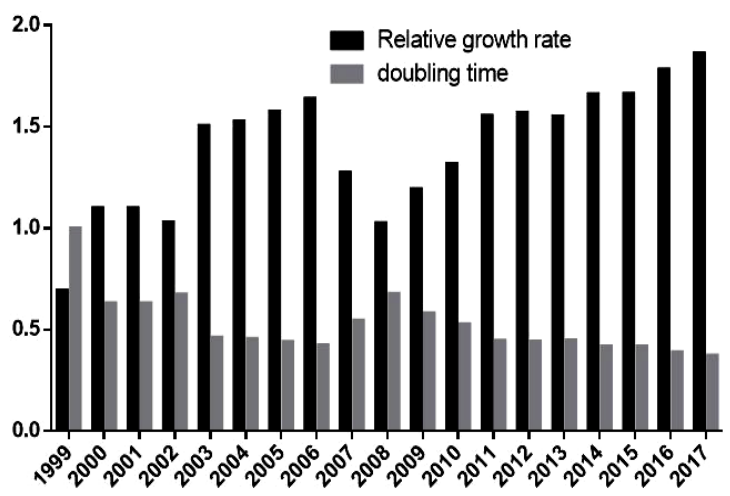

Figure 3: Relative Growth Rate (RGR) and Doubling Time (DT) of nanotechnology publications in Jordan

\section{Doubling time (DT)}

The DT outputs of nanotechnology in Jordan have a decreasing trend (Figure 3). However, from 1999 to 2007, the values fluctuated. It then 
decreased linearly between 2008 and 2019. The DT of scientific research in Jordan was 0.37 in 2019.

\section{Compound annual growth rate (CAGR)}

The CAGR of intellectual scientific research papers collected during the period between 1998 and 2019 in Jordan was $33 \%$.

\section{Trend line analysis}

Trend line analysis was conducted on the development of nanotechnology research in Jordan in the period, 2014 - 2019. The analysis indicated that the trend from 2014 until 2019 was more into a linear correlation with a coefficient of determination $\left(R^{2}\right)$ equal to 0.9638 (Figure 4). So, the data were fitted into a linear regression, then the equation:

$(\gamma=8,0024 X-6041.9)$ was used to predict the future number of publications until 2025. According to the equation, the predicted number of scientific Jordanian publications in nanotechnology for the year 2025 will be 472 .

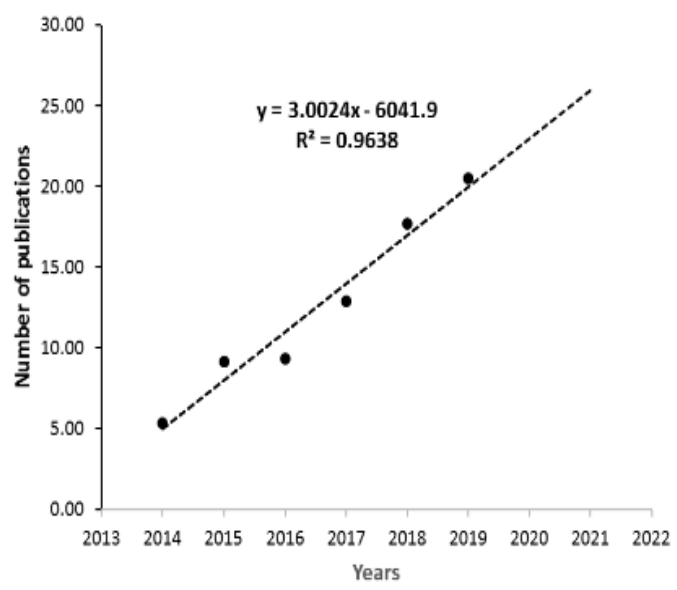

Figure 4: Analysis of nanotechnology publications growth in Jordan between 2014 - 2019. Data of the cumulative number of publications were fitted into a linear regression

\section{Distribution according to the subject area}

The published articles were sorted according to the following research fields: material science, engineering, physics and astronomy, chemical engineering, computer science, pharmacology, biochemistry and genetics, environmental science, energy, and other fields. Figure 5 shows the percentage of distribution in each research area.

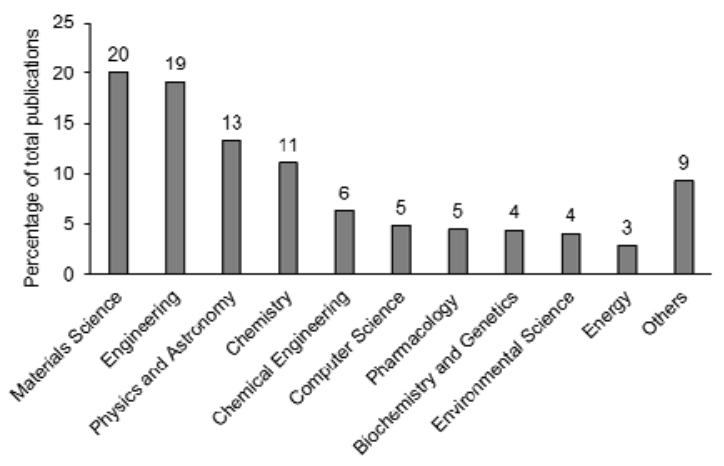

Figure 5: Distribution of published nanotechnology research by subject area (2014 - 2019)

\section{DISCUSSION}

Nanotechnology research is contributed by two main sectors: academia and the industry. In the academic sector, which contributes to the vast majority of nanotechnology publications (98\%), at least 40 research labs are producing or manipulating nanoparticles, leaving the remaining $2 \%$ to the industrial sector. Nanotechnology research in Jordan is growing swiftly, and that was visible as more than $50 \%$ of the total number of publications was contributed in the last three years (2017-2019). Jordan's RGR (1.96 in 2019) is not far from the world $R G R$ in nanotechnology publications (2.04 in 2016) [16].

The same result was reached using Doubling time (DT), which may be utilized as a tool to measure the growth rate of scientific literature. The DT of scientific research in Jordan was 0.37 in 2019 , and it is very close to the worldwide DT in 2019 (0.33) [16].

The estimated CAGR for the global nanotechnology publications was $30.7 \%$ from 1990 to 2014 [16]. Another piece of evidence shows that Jordanian researchers are interested in nanotechnology. This can be inferred from the growth of nanotechnology research compared to the total number of scientific researches in Jordan. Moreover, the results denote that nanotechnology research in Jordan is increasing dramatically. Consequently, the need for regulations and legislation for nanotechnology research in Jordan is urgent. However, before discussing what sort of regulations and legislations Jordan needs, it is significant to emphasize the future of nanotechnology in Jordan.

To further understand the future of nanotechnology in Jordan, trend line analysis is inevitable, as it constitutes a valuable tool in 
technical analysis for both trend identification and confirmation, which may later be used for prediction. Consequently, the expected percentage of publications to be produced between 2020 - 2025 was $65 \%$ of the total nanotechnology publications in Jordan for the period, 1994 - 2025. In short, the vast majority of nanotechnology research in Jordan is to be produced in the future.

The future of nanotechnology research in Jordan is prosperous. Nevertheless, it is necessary to scrutinize the nature and the perceived public health impact of nanotechnology research in the industrial as well as the academic sector.

There are lots of products containing nanomaterials used in our daily life [18]. For instance, Silver nanoparticles (Ag NPs) have been used in diverse applications including air sanitizer sprays, wet wipes, food storage containers, shampoos, and toothpaste. However, several studies had reported that Ag NPs demonstrated dosage-dependent cytotoxicity to humans and cell lines[19, 20]. Furthermore, several nanoparticles are under research and being evaluated as additives in personal care products. Despite that, their hazardous effects on humans (if there is any) are unknown [5]. Electronic devices, sports equipment, composite plastics, textiles, anti-bacterials, kitchenware, paints, coatings, composite, composite plastics, tires, and fuel additives are examples of consumer products containing nanomaterials [21], and such products are available in the Jordanian market and industries.

In the industrial sector, the most vulnerable group are the workers due to their high exposure during the production processes. The toxicity is probably due to inadequate protection, working in non-enclosed systems, and handling powdered nanomaterials during the maintenance of the instruments that are used to fabricate and synthesize nanomaterials [22]. Furthermore, individuals have a knowledge deficit of the potential risk. Neither the workers, policymakers nor the consumers of nanotechnology have a clear understanding of the toxicity of what they are exposed to. The knowledge deficit about nanotechnology's potential hazards may be due to the fact that most nanotechnology-oriented research is executed by physicists and engineers who do not pay attention to the potential hazards.

Similar to its status in the industrial sector, nanotechnology is one of the central research interests in academia worldwide [23]. In 2019, more than $8 \%$ of the total publications in Jordan were related in one way or the other to nanotechnology. This is clear in the arduous number of publications (2014 - 2019), and the slope of the trendline.

While this implies that nanotechnology research has a prosperous future in Jordan, as well as other developing countries, it is undeniable that such an academic interest is perilous. When conducting nanotechnology research, most Jordanian researchers and professors do not pay careful attention to potential toxicity. Most nanotechnology research in the Jordanian academia focuses on how to develop new nanomaterials without considering the healthoriented issues and risks associated with such a development. As illustrated in Figure 5, more than $90 \%$ of published research focused on the applications or synthesis of nanomaterials, rather than studying the fate of the nanomaterials.

Nanotechnology is viewed in Jordan as a national priority [24]. However, without any regulation or legislation to control nanotechnology research, in addition to knowledge deficit, involvement in nanotechnology research encourages the public to obtain nanotechnology products and materials without considering their potential toxicity.

The nanotechnology craft could be hazardous However, it can be regulated to be safe to the public. It is therefore expected that the Jordanian government would adopt a set of safety procedures without aborting or decreasing the growth of the nanotechnology industry or research. That set of regulations may include some entries, such as adopting regulations from the US and the EU regulating the importation of raw nanomaterials by demanding a clear material safety data sheet (MSDS) showing the toxicity of such materials, focusing on nanomaterials' direct effect on human cells and decomposition in nature such as it is done in the European Union (EU) [25].

Moreover, spreading awareness of potential nanotoxicity to the public is a crucial step using social media, awareness campaigns, and curricula. At the academic level, it is feasible that the Jordanian universities and research institutions cooperate in establishing a central research center or institute (i.e. in Amman). That sort of research center should host all nanotechnology instrumentations, and be funded by the government and the universities. Furthermore, it should be accessible to researchers from different universities, and have boards and employees with experience in nanomaterials handling and toxicity. Additionally, the center can function as one of the main 
reliable sources for spreading the awareness of nanotechnology and its hazards. Eventually, this center will be qualified enough to function as the main legislator of nanotechnology research in Jordan.

The proposed center should have an institutional review board (IRB), which is responsible for evaluating and controlling nanotechnology research and industry.

\section{CONCLUSION}

Nanotechnology research in Jordan is growing rapidly at a level similar to worldwide growth. However; it ignores the resulting public health threats. Taking into consideration the inevitable needs of the developing countries, including Jordan to have nanotechnology and deploy it by every possible means, the many academic nanotechnology publications emphasize the industrial development of nanotechnology at the cost of nanomaterials' biological effects, which could constitute a problem with regards to public health in the long run. Most nanotechnology publications focus on how to make use of nanomaterials with less consideration of the health-oriented side effects. As a result, it is a national necessity to adopt regulations and legislations at the governmental and institutional levels in a country like Jordan, that warns people (producers and consumers) against the health risks of nanomaterials and control the nanotechnology research and craft.

\section{DECLARATIONS}

\section{Conflict of interest}

No conflict of interest is associated with this work.

\section{Contribution of authors}

We declare that this work was done by the authors named in this article, and all liabilities pertaining to claims related to the content of this article will be borne by the authors. Yazan Akkam, designed the study, supervised the data collection, and analyzed the data; interpreted the data and prepared the manuscript; Moawiah Khatatbeh analyzed the data and reviewed the draft of the manuscript. All authors read and approved the manuscript.

\section{Open Access}

This is an Open Access article that uses a funding model which does not charge readers or their institutions for access and distributed under the terms of the Creative Commons Attribution License (http://creativecommons.org/licenses/by/ 4.0) and the Budapest Open Access Initiative (http://www.budapestopenaccessinitiative.org/rea d), which permit unrestricted use, distribution, and reproduction in any medium, provided the original work is properly credited.

\section{REFERENCES}

1. Shukla AK, editor. Nanoparticles and their Biomedical Applications. Springer Nature; 2020 Mar 6.

2. Adiguze Ol. Nanotechnology 2020 Market Analysis. in 18th International Conference on Nano Technology and Nano Engineering 2020; Venice, Italy.

3. Chen C, Li YF, Qu Y, Chai Z, Zhao Y. Advanced nuclear analytical and related techniques for the growing challenges in nanotoxicology. Chem Soc Rev 2013; 42(21): 8266-8303.

4. Zurutuza A, Marinelli C. Challenges and opportunities in graphene commercialization. Nat Nanotechnol 2014; 9(10): 730-734.

5. Jeevanandam J, Barhoum A, Chan YS, Dufresne A, Danquah MK. Review on nanoparticles and nanostructured materials: history, sources, toxicity and regulations. Beilstein J Nanotechnol 2018; 3; 9(1): 10501074.

6. Yi X, Gao H. Cell interaction with graphene microsheets: near-orthogonal cutting versus parallel attachment. Nanoscale 2015; 7(12): 5457-5467.

7. Khan FH. Chemical Hazards of Nanoparticles to Human and Environment (A Review). Oriental J Chemistry 2017; 29(4): 1399-1408.

8. Kim KT, Tanguay RL. The role of chorion on toxicity of silver nanoparticles in the embryonic zebrafish assay. Environ Health Toxicol 2014; 29: e2014021.

9. Kim MS, Louis KM, Pedersen JA, Hamers RJ, Peterson $R E$, Heideman W. Using citrate-functionalized $\mathrm{TiO}_{2}$ nanoparticles to study the effect of particle size on zebrafish embryo toxicity. Analyst 2014; 139(5): 964972.

10. Poulsen SS, Knudsen KB, Jackson P, Weydahl IE, Saber $A T$, Wallin $H$, Vogel $U$. Multi-walled carbon nanotubephysicochemical properties predict the systemic acute phase response following pulmonary exposure in mice. PloS one 2017;12(4): e0174167.

11. Wang Y, Santos A, Evdokiou A, Losic D. An overview of nanotoxicity and nanomedicine research: principles, progress and implications for cancer therapy. J Mater Chem B 2015; 3(36): 7153-7172.

12. Kolosnjaj-Tabi J, Just J, Hartman KB, Laoudi $Y$, Boudjemaa S, Alloyeau D, Szwarc $H$, Wilson LJ, Moussa F. Anthropogenic carbon nanotubes found in the airways of Parisian children. EBioMedicine 2015; 2(11): 1697-1704.

13. Hodson L, Methner M, Zumwalde RD. Approaches to safe nanotechnology; managing the health and safety

Trop J Pharm Res, February 2021; 20(2): 430 
concerns associated with engineered nanomaterials 2009.

14. Assaf AA. The Effect of Macroeconomic Variables on Jordan's Economic Growth. Eur J Soc Sci 2014; 42(1): 101-111.

15. Verma MK, Shukla R. Mapping the research trends on information literacy of selected countries during 20082017: A scientometric analysis. DESIDOC Journal of Library \& Information Technology 2019; 1;39(3): 125130

16. Velmurugan C, Radhakrishnan N. Visualizing Global Nanotechnology research on publication deeds, 19892014. Library Philosophy and Practice. 2016: 1.

17. Alshamaileh E, Al-Sulaibi M, Al-Khawaldeh $A$, Almatarneh MH, El-Sabawi D, Al-Rawajfeh A. Current status of nanotechnology in Jordan. World $j$ sci technol 2016; 13(2): 66-81.

18. Wijnhoven SW, Dekkers S, Hagens WI, De Jong WH. Exposure to nanomaterials in consumer products. RIVM letter report 340370001. 2009 Sep 4.

19. Ema M, Okuda $H$, Gamo M, Honda K. A review of reproductive and developmental toxicity of silver nanoparticles in laboratory animals. Reprod Toxicol 2017; 67: 149-164

20. Skalska J, Strużyńska L. Toxic effects of silver nanoparticles in mammals-does a risk of neurotoxicity exist. Folia Neuropathol 2015; 53(4): 281-300.

21. Development, O.f.E.C.-o.a., recycling of waste containing nanomaterials, in Working Party on Resource Productivity and Waste. 2013: france.

22. Roubert F, Beuzelin-Ollivier MG, Hofmann-Amtenbrink M, Hofmann H, Hool A. "Nanostandardization" in action: implementing standardization processes in a multidisciplinary nanoparticle-based research and development project. NanoEthics 2016; 10(1): 41-62.

23. Alfeeli B, Bumajdad A, Al Lawati $H$, Abdelgawad $M$, Baccar ZM, Salem IB, Benaskar F. A review of nanotechnology development in the Arab World. Nanotechnol Rev 2013; 2(3): 359-377.

24. National priorities-Scientific research supports funds. 2017; Available from: http://www.srf.gov.jo/Nationalpriorities.

25. Rauscher $H$, Rasmussen $K$, Sokull-Klüttgen $B$. Regulatory aspects of nanomaterials in the EU. Chem Ing Tech 2017; 89(3): 224-231. 